\title{
New White Gold Alloys
}

\author{
THEIR DEVELOPMENT ON THE BASIS OF \\ QUANTITATIVE COLOUR ASSESSMENT
}

\author{
I. Bruce MacCormack and John E. Bowers \\ BNF Metals Technology Centre, Wantage, U.K.
}

\begin{abstract}
Modification of the colour of gold by the addition to it of other metals is important for jewellery applications. The potential of modern equipment for measuring spectral reflectance for the identification of promising new white carat gold compositions is illustrated by this account of a study of the bleaching and other effects of various metals incorporated in 18 carat jewellery alloys containing 10 per cent palladium.
\end{abstract}

White gold alloys were originally developed as substitutes for platinum and are mainly used for jewellery manufacture. Alloys based on the goldsilver-copper system are used for yellow gold jewellery, but the system is unsuitable as a basis for white alloys, as good colour cannot be achieved in a high carat composition, and low carat alloys bleached by adding a high proportion of silver have poor tarnish resistance. Consequently, other elements are used in commercial white gold alloys and these materials fall into two groups, one in which the major bleaching element is nickel and the other in which it is palladium. White gold alloys containing large amounts of nickel do not have the deformation characteristics desired for jewellery manufacture, because of the strong hardening effect of nickel. It is possible to achieve a better combination of colour and mechanical properties in white golds by bleaching with palladium, but since the price of palladium is about 1000 times that of nickel, these better alloys are more costly. An 18 carat gold alloy with 10 per cent palladium costs about 5 per cent more than a similar alloy with 10 per cent nickel.

Commercial compositions usually result in a compromise between adequate workability and a nearwhite colour. Finished items are then electroplated with rhodium to improve the colour. This practice has the advantage of masking the differences in colour between parts of a joined article and the brazing alloy. However, the contrast between the colour of the coating and that of the substrate can lead to complaints from customers if it is revealed by wear.

There is clearly a need for white gold alloys (and brazing alloys) sufficiently good in colour for rhodium plating to be unnecessary and with other properties that meet the needs of jewellery fabrication. This article attempts to define the colour requirements of such alloys and briefly outlines the results of research on a range of compositions, some of which may prove to be suitable for commercial exploitation.

\section{Characterization of Alloy Colour}

McDonald and Sistare, in discussing the metallurgy of both coloured (1) and nickel-containing white gold alloys (2), have considered briefly and qualitatively the colour of these materials. This approach has been extended to palladium-containing white gold alloys by Susz and Linker (3). However, in order to present the data available on gold alloys in useful form, it is necessary to quantify their colour in a simple and meaningful way.

Colorimetry, the science of colour measurement (4), has been developed for the paint, plastics and

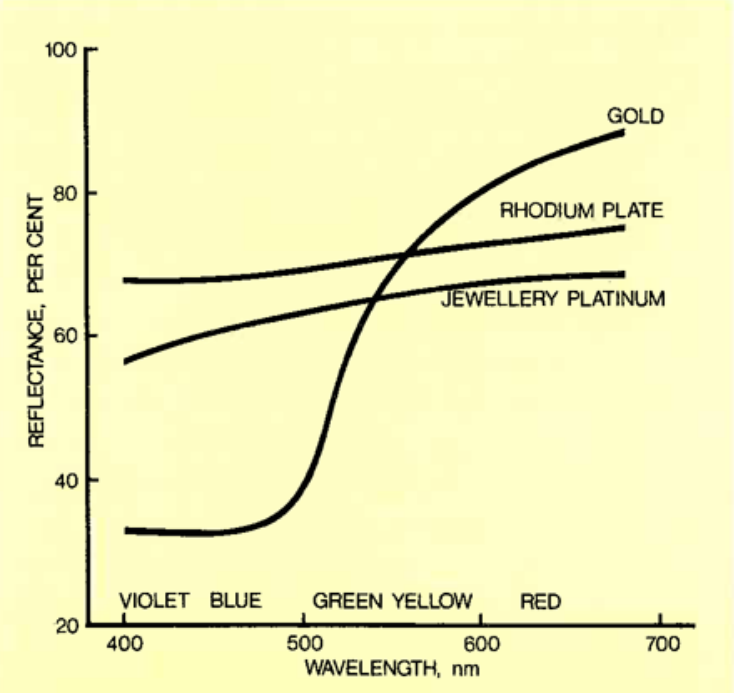

Fig. 1 Experimental spectral reflectance curves for pure gold, electrodeposited rhodium and for the 95 platinum/5 copper weight per cent alloy 


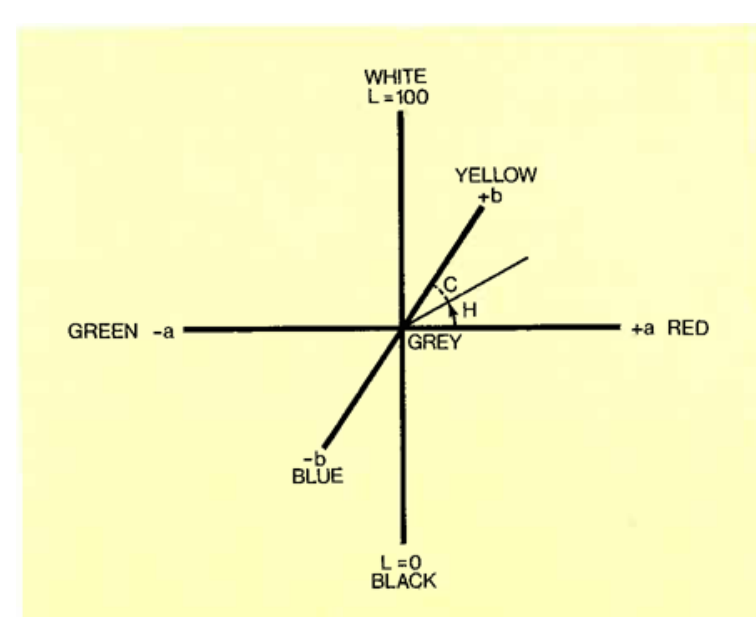

Fig. 2 The three-dimensional CIELAB system of orthogonal colour co-ordinates. After (11)

textile industries where it is necessary to ensure good colour matching of products made at different times. Colour can be defined by a spectral reflectivity curve (Figure 1), but this does not indicate the overall effect perceived by the human eye. This latter type of information is more usually presented as three co-ordinates which define colour as two Cartesian co-ordinates in a planar chromaticity diagram, while the third coordinate is a measure of the overall brightness or luminance. At the centre of the chromaticity diagram is the white point, which is defined by the nature of the illuminant used in the colour measurements. Spectral colours of 100 per cent saturation lie on the periphery of the plot. Any given colour can be reproduced by mixing white light with the appropriate spectrally pure colour; the higher the proportion of the latter, the greater the degree of saturation.

There are several systems of colour co-ordinates, depending on the choice of mathematical functions employed to derive their values from spectral reflectance measurements. In the Commission Internationale de l'Éclairage (CIE) system, the chromaticity chart falls in the first quadrant of Cartesian space whose co-ordinates are, by convention, labelled $\mathrm{x}$ and $y$; the third co-ordinate is the luminance $\mathrm{Y}$. In the CIELAB representation (Figure 2), all four quadrants are occupied and the white point lies at the intersection of abscissa, a, and ordinate, $b$. The third orthogonal co-ordinate, the lightness $\mathrm{L}$, is closely related to luminance and is a measure of the brightness of the sample, varying from 0 for black to 100 for white. This system has the advantage that, when expressed in polar co-ordinates, the distance $\mathrm{C}$, known as the metric chroma, is a direct measure of the departure from whiteness of the sample, while the spectral colour towards which it deviates is indicated by the metric hue angle $\mathrm{H}$.
In recent years, colorimetry has been applied to the measurement of the colour of metals and alloys with great success. Gardam $(5,6)$ has demonstrated that metals are characteristically highly desaturated, or pale in hue, and of very high luminance or lightness. Roberts and Clarke (7) have employed the technique of spectroellipsometry to determine the optical constants and hence define the CIE colour co-ordinates of gold-silver-copper alloys, the basis of most yellow gold jewellery, and the significance of these results for both single and two-phase compositions was discussed in relation to the electronic structure and appearance of such alloys by Roberts, Clarke and Hunt (8). Following this work, German, Guzowski and Wright $(9,10,11)$ used a computerized spectrophotometer to calculate CIELAB co-ordinates for alloys of the same metallurgical system and established topological colour maps. The technique was used to determine the tarnish resistance of dental gold alloys based on the gold-silver-palladiumplatinum-copper-zinc system and the possibility of designing alloy compositions to meet specific colour objectives was examined.

To characterize alloy colour, Roberts and Clarke (7) used the artificial daylight illuminant $\mathrm{C}$ and presented their results in terms of the CIE coordinates $\mathrm{x}, \mathrm{y}$ and $\mathrm{Y}$, while German et al. $(9,10,11)$ employed illuminant D65, a later development which is more realistically representative of daylight, and quoted CIELAB co-ordinates $\mathrm{L}$, a and $\mathrm{b}$. Maximum benefit can only be derived from studies of this sort by introducing a degree of standardization to the instrumentation and measurement techniques and to the method of presentation of the information. While conversion formulae do exist, a unified system of presentation would greatly facilitate comparison of data.

In our work on the development of white gold alloys, we used the spectrophotometry facilities of Instrumental Colour Systems Ltd., Newbury, U.K., to measure the colour co-ordinates of experimental alloys, using the illuminant D65. The CIELAB co-ordinates $\mathrm{L}, \mathrm{C}$ and $\mathrm{H}$ were computed and are considered to give the simplest representation of the colour of alloys which are all based on gold and have colours between that of pure gold and white. Thus, for these alloys, the hue angles are similar and lie between 82 and $86^{\circ}$. Similarly, these alloys have a lightness $\mathrm{L}$ of between 83 and 85 . Hence, when discussing white golds, whiteness can to a good first approximation be defined by the metric chroma. It is then a simple matter to compare the whiteness of alloys: white is 0 , the 95 platinum $/ 5$ copper weight per cent alloy is 4 and pure gold is about 40 (Table I). A good white gold alloy would have a metric chroma of less than 9 and an alloy with a value below 6 would be of excellent white colour. 
Table I

CIELAB Co-Ordinates of Reference Materials and of Experimental White Gold Alloys

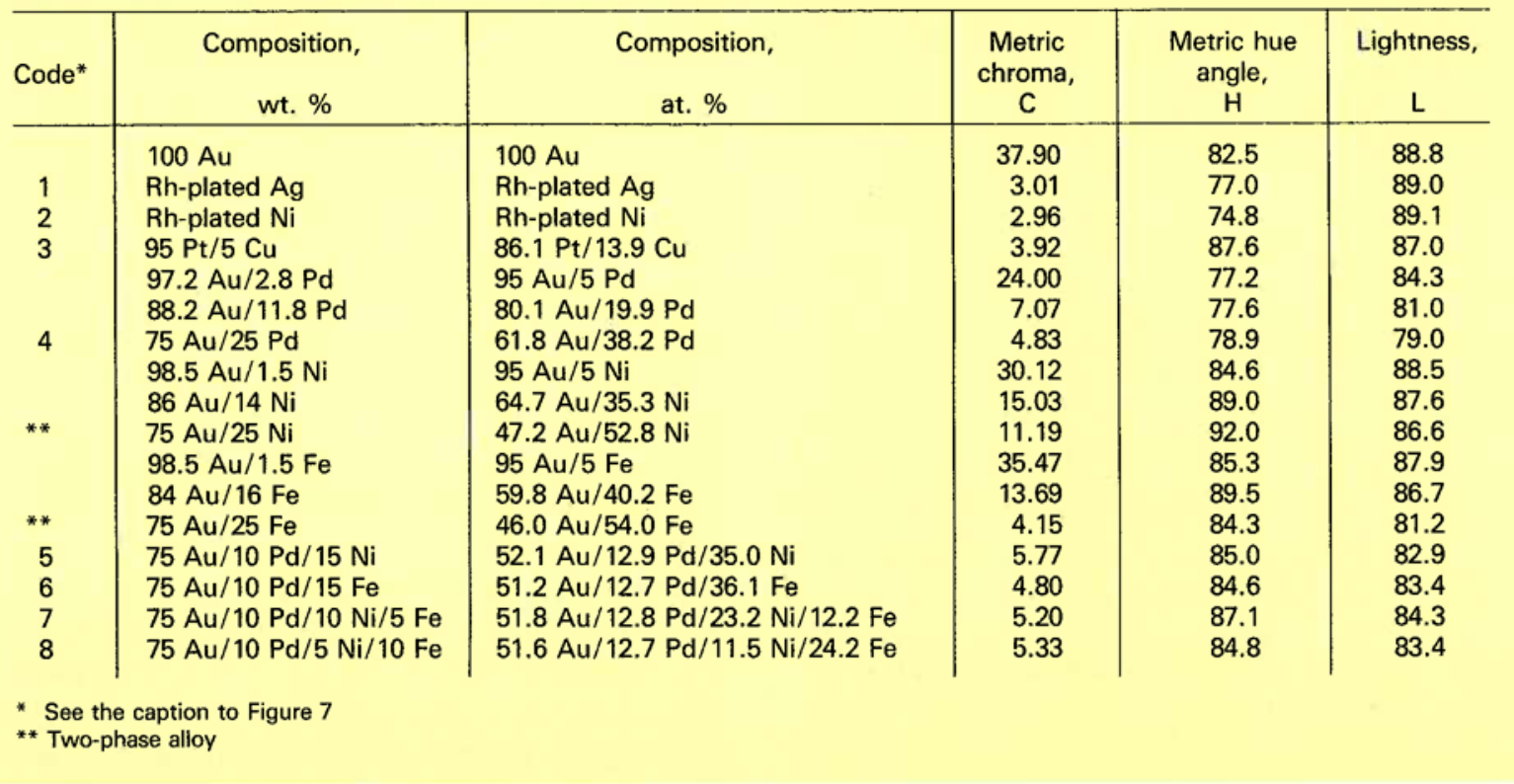

As the colours of white gold alloys can be compared in this way, using the one parameter metric chroma, it is possible to employ regression analysis to define empirically the relative bleaching effectiveness of individual alloying additions to a gold matrix. Thus, it is ultimately possible to predict the chroma for a given alloy composition.

The simple definition of colour by the metric chroma alone may not be adequate when considering coloured gold alloys, particularly those containing a substantial amount of copper, since this element tends to produce red hues, so that the hue angle is reduced. A quantitative colour assessment could still be given using the CIELAB system, but it would be necessary to quote values of $\mathrm{H}$ and of $\mathrm{C}$.

\section{Primary Bleaches of Gold}

The bleaching effect of various elements alloyed with gold has been investigated qualitatively by O'Connor $(12,13)$ and the colour of a number of his samples, together with new ones prepared by the authors, was measured quantitatively in this study. Of particular interest are binary alloys of gold with the two principal commercial bleaches, palladium and nickel, and with iron. The CIELAB co-ordinates, $\mathrm{L}, \mathrm{C}$ and $\mathrm{H}$, of gold-palladium, gold-nickel and goldiron binary alloys are shown in Table I and their metric chromas are plotted as a function of atomic composition in Figure 3. The most diluted composition in each series corresponds to the 18 carat (that is, 75 per cent gold by weight) alloy. The 18 carat goldnickel and gold-iron alloys have a two-phase struc- ture, the measured colour being the average of the colours of the gold-rich and base metal-rich phases. The decolouring effects of palladium and nickel are not simple linear functions of their concentration. The superiority of palladium as a bleaching agent is

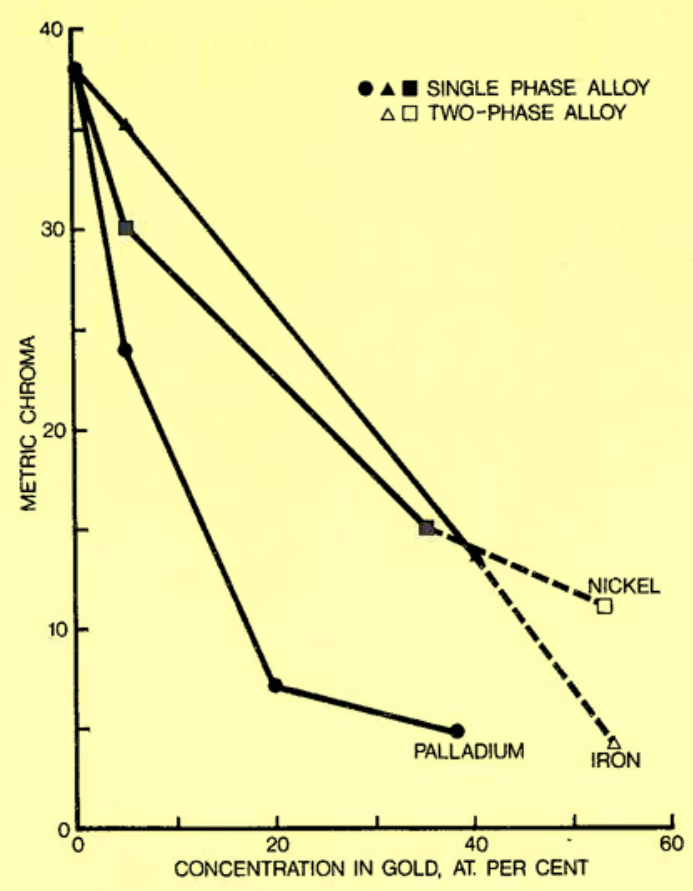

Fig. 3 Metric chroma of binary gold-palladium, gold-nickel and gold-iron alloys 


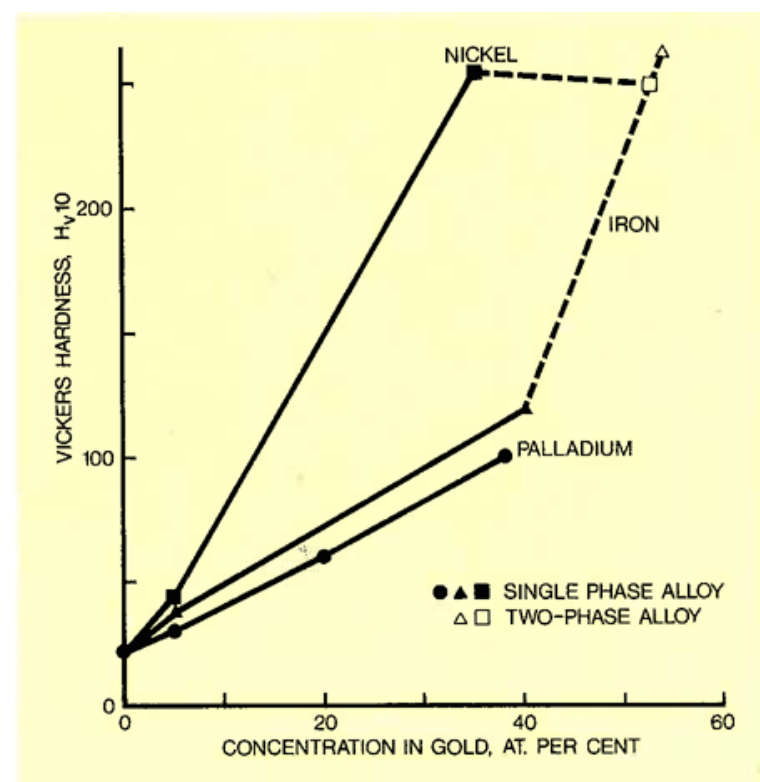

Fig. 4 Vickers hardness of binary gold-palladium, gold-nickel and gold-iron alloys after annealing at $700^{\circ} \mathrm{C}$ and water quenching

clearly demonstrated by the data in Table I and Figure 3, but it should be noted that the atomic mass of palladium is roughly twice that of nickel and iron, and in terms of weight per cent of element added to the gold, the difference in decolouring effectiveness is less marked. Nickel and iron have comparable bleaching properties, particularly towards the limits of their solid solubilities in gold and, since the principal objection to nickel-containing white golds is

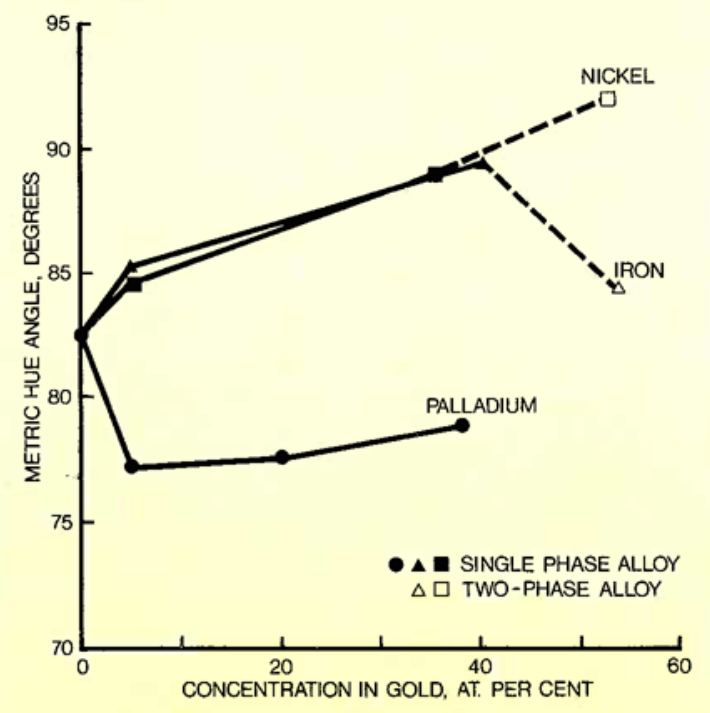

Fig. 5 Metric hue angle of binary gold-palladium, gold-nickel and gold-iron alloys their excessive hardness, it is useful to consider the Vickers hardness values of the same three series of alloys in the annealed condition (Figure 4). The in crease in hardness is, to a good approximation, a linear function of the atomic percentage of alloying element present, provided the alloy retains a singlephase structure. The strong hardening effect of nickel is clearly demonstrated in Figure 4, while it may be noted that this effect is much weaker with palladium and iron. The combination of colour and hardness data suggests that 18 carat white gold alloys containing iron as a major bleaching additive could have the desirable physical characteristics normally associated with palladium-rich white gold alloys. Ironcontaining gold alloys would also be cheaper than the existing palladium-containing jewellery white gold alloys.

The influence of these alloying elements on the CIELAB hue angle and lightness was also determined. The binary gold-palladium alloys all have lower hue angles (more red tint) and lightnesses than pure gold, while nickel and iron increase the hue angle (more yellow tint) and only slightly lower the lightness (Figures 5 and 6). The combination of these effects may well explain the observation of Susz and Linker (3) that palladium white gold alloys have 'warm, grey overtones' compared with the 'cold steely appearance' of their nickel-containing counterparts.

\section{Carat White Gold Alloys}

Further 18 carat alloys, containing more than one of the elements palladium, nickel and iron, were prepared and the CIELAB co-ordinates of these alloys and of pure gold, 95 platinum $/ 5$ copper weight per cent alloy, and rhodium-plated specimens of silver and nickel are presented in Table I. Even when the entire 25 per cent by weight of additives in an 18 carat alloy consists of one or more of the most effective primary bleaching elements (palladium, nickel and iron), the best chroma that can be achieved in a single-phase composition is about 5 . A target of 6 is more realistic when small amounts of such elements as copper and zinc are included to improve the workability and lower the hardness and the liquidus temperature to values acceptable to the jewellery industry. For comparison, the metric chromas of 95 platinum $/ 5$ copper weight per cent alloy and rhodium plate are about 4 and 3 respectively. In samples of similar hue angle and lightness, a chroma difference of 1 is just discernible to the human eye if the samples are placed side by side. Thus, the best possible white gold alloys will inevitably appear less white than either 95 platinum $/ 5$ copper alloy or rhodium plate in a direct comparison test. However, alloys of chroma below about 9 are of pleasing white appearance and should be suitable for the fabrication of 
jewellery articles which would not require rhodium plating, provided compatible brazing alloys of good colour can be developed.

The colours of a series of commercial 18 carat white gold alloys have been measured and their positions on the CIELAB C-H chromaticity chart are shown in Figure 7. The metric chromas of these alloys vary from 6 to 15, the four whitest compositions containing 12 to 17 per cent palladium by weight. Even the least expensive alloys contain up to 6 per cent palladium, but they have a chroma of 10 or more, combined with rather high hardness values.

We have attempted to develop an improved 18 carat white gold alloy containing 10 per cent palladium by weight. The composition of the remaining 15 per cent was systematically varied and the best combination of properties was achieved using iron as an additional bleaching agent. The optimum composition range was 75 gold/ 10 palladium $/ 5$ to $10 \mathrm{iron} /$ 0 to 10 copper $/ 0$ to 10 silver $/ 0$ to 5 zinc weight per cent, giving alloys of hardnesses of 120 to $150 \mathrm{H}_{\mathrm{v}}$ after annealing at $800^{\circ} \mathrm{C}$ and quenching, and metric chromas from 6 to 9 . The metric hue angle varied from 82 to $86^{\circ}$ and the lightness ranged from 83 to 85 ; the position of these experimental alloys on the CIELAB chromaticity diagram is also shown in Figure 7. Their whiteness is comparable with that of the best commercial samples analyzed and the fact that they contain from 2 to 7 per cent less palladium is clearly of economic significance. The new alloys are also generally of lower hardness than commercial alloys currently in use. Depending on the outcome of assessment by manufacturing jewellers, they could find application in the jewellery industry.

\section{Conclusions}

The suitability of spectrophotometry for quantifying the colour of metals and alloys has been established further and it is suggested that the CIELAB

Fig. 7 Position of single-phase 18 carat gold alloys in the CIELAB C-H colour diagram
1 Rhodium-plated silver
2 Rhodium-plated nickel
395 platinum/5 copper weight per cent
475 gold/25 palladium weight per cent
575 gold/10 palladium/15 nickel weight per cent
675 gold/10 palladium/15 iron weight per cent
775 gold/10 palladium/10 nickel/5 iron weight per cent
875 gold/10 palladium/5 nickel/10 iron weight per cent
9 Commercial palladium-rich 18 carat white gold alloy
10 Commercial nickel-rich 18 carat white gold alloy
11 Other commercial 18 carat white gold alloys

The shaded area corresponds to experimental 18 carat white golds in the composition range 75 gold/10 palladium $/ 5$ to 10 iron/0 to 10 copper/0 to 10 silver/ 0 to 5 zinc

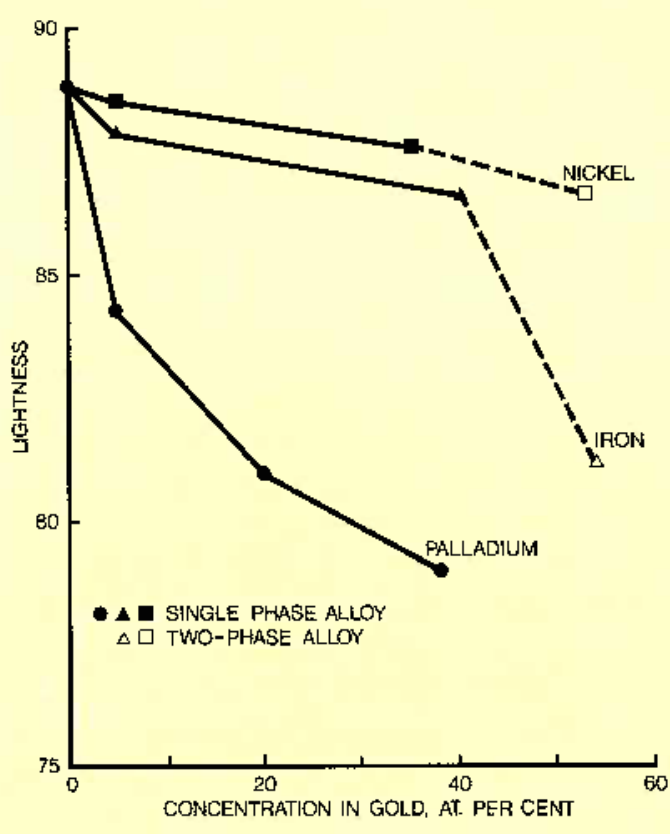

Fig. 6 Lightness of binary gold-palladium, goldniekel and gold-iron alloys

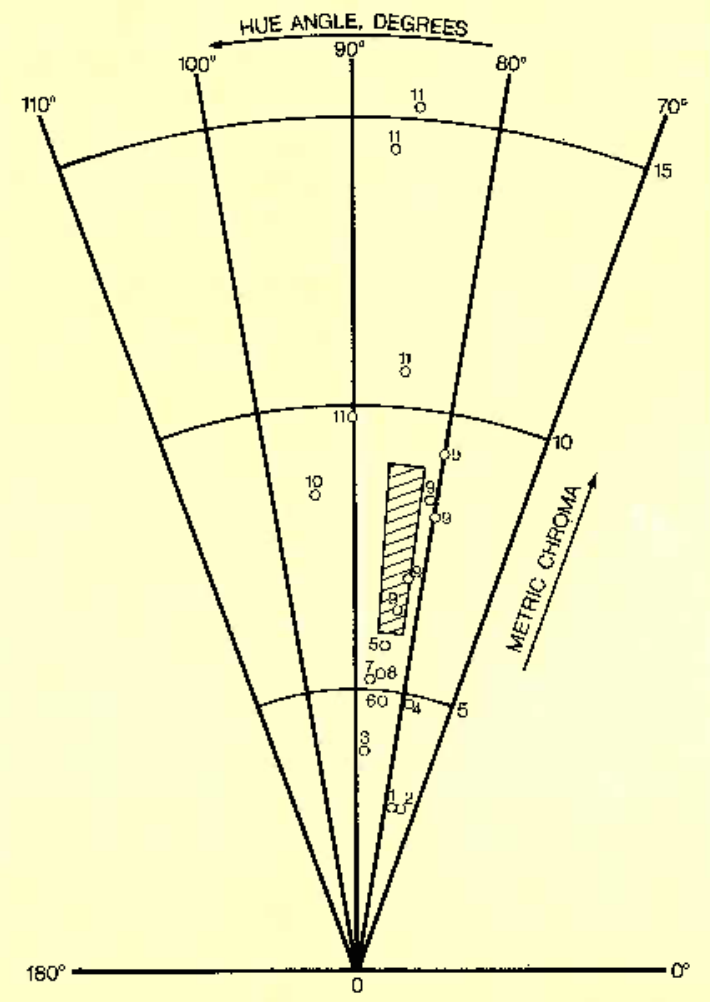


co-ordinates $\mathrm{L}, \mathrm{C}$ and $\mathrm{H}$ represent a simple and most meaningful way of presenting colour data, particularly when discussing white gold alloys. The metric chroma, $\mathrm{C}$, is to a good first approximation a measure of the degree of whiteness of any such alloy, as $L$ and $\mathrm{H}$ are virtually the same for all the alloys that are commercially interesting.

A comparison of the bleaching and hardening effects of palladium, nickel and iron when alloyed with gold has been carried out and the suitability of iron as a major additive has been demonstrated. Iron is economically more attractive than palladium and does not harden the alloy as much as nickel.

The colours of the whitest of the experimental alloys and some commercially available 18 carat white gold alloys have been compared with the colours of the 95 platinum $/ 5$ copper weight per cent alloy and of rhodium-plated surfaces. While slightly less white than the platinum alloy or rhodium plate, the new alloys are similar in appearance to the better white golds currently available and appear to have potential for the production of aesthetically pleasing jewellery articles which do not require plating.

The results of this research indicate that alloys in the composition range 75 gold $/ 10$ palladium $/ 5$ to 10 iron $/ 0$ to 10 copper/0 to 10 silver $/ 0$ to 5 zinc weight per cent may prove the best, having hardness values between 120 and $150 \mathrm{H}_{\mathrm{v}}$ after a suitable anneal, and metric chromas of 6 to 9 . The properties of such alloys match those of more costly commercial alloys containing substantially more palladium.

\section{Acknowledgements}

This work was sponsored by the International Gold Corporation Limited. The authors also wish to acknowledge the guidance received from the Goldsmiths' Research Foundation throughout this study.

\section{References}

1 A. S. McDonald and G. H. Sistare, Gold Bull., 1978, 11, (3), 66-73

2 A. S. McDonald and G. H. Sistare, Gold Bull., 1978, 11, (4), $128-131$

3 C. P. Susz and M. H. Linker, Gold Bull., 1980, 13, (1) 15-20

4 'The ICS Manual of Industrial Colour Measurement', Instrumental Colour Systems Ltd., Newbury, U.K., 3rd edition, 1978

5 G. E. Gardam, Trans. Inst. Met. Finish., 1964, 41, 190-199

6 G. E. Gardam, Trans. Inst. Met. Finish., 1966, 44, 186-188

7 E. F. I. Roberts and K. M. Clarke, Gold Bull., 1979, 12, (1), 9-19

8 E. F. I. Roberts, K. M. Clarke and R. Hunt, Mater. Sci. Eng., $1980,42,71-80$

9 M. M. Guzowski, D. C. Wright and R. M. German, presentation to the Third International Precious Metals Conference, Chicago, IL., U.S.A., May 1979

10 R. M. German, M. M. Guzowski and D. C. Wright, f. Met., $1980,32,20-27$

11 R. M. German, M. M. Guzowski and D. C. Wright, Gold Bull., 1980, 13, (3), 113-116

12 G. P. O'Connor, Gold Bull., 1978, 11, (2), 35-39

13 G. P. O'Connor, Met. Technol., 1979, 6, 261-266 